\title{
Erratum to: The incidence of deep vein thrombosis and pulmonary embolism following cast immobilisation and early functional bracing of Tendo Achilles rupture without thromboprophylaxis
}

\author{
G. J. Heyes • A. Tucker $\cdot$ A. L. R. Michael • \\ R. G. H. Wallace
}

Published online: 26 July 2014

(C) Springer-Verlag Berlin Heidelberg 2014

\section{Erratum to: Eur J Trauma Emerg Surg}

DOI 10.1007/s00068-014-0408-5

The original version of this article unfortunately contained wrong values.

Section "Discussion", second paragraph, third sentence should read:

The incidence of DVT after completion of our treatment protocol was $1.1 \%$ and the incidence of PE was $0.32 \%$.

The online version of the original article can be found under doi:10.1007/s00068-014-0408-5.

G. J. Heyes $(\square)$

Apartment 1001, 70 Chichester Street, Belfast, Co. Antrim BT1 4JQ, Northern Ireland, UK

e-mail: gjheyes@live.co.uk

A. Tucker · A. L. R. Michael

400, Sandygate Road, Sheffield, South Yorkshire S10 5UE, UK

e-mail: alrexmichael@yahoo.co.uk

A. Tucker - A. L. R. Michael

Northern General Hospital, Herries Road, Sheffield,

South Yorkshire S5 7AU, UK

A. Tucker · R. G. H. Wallace

Department of Trauma and Orthopaedics, Ulster Hospital

Dundonald, Upper Newtownards Road, Dundonald,

Belfast BT16 1RH, UK

e-mail: r.wallace@dnet.co.uk

R. G. H. Wallace

8, My Lady's Mile, Holywood, Northern Ireland,

Co. Down BT18 9EW, Northern Ireland, UK 